\title{
Influence of Negative Transfer of Mother Tongue on Chinese English Learners' Pronunciation
}

\author{
Tingting Zheng \\ Zhejiang Ocean University, Zhoushan, China \\ Qi'ang Liu \\ Foreign Language College, Zhejiang Ocean University, China
}

\begin{abstract}
In our modern society, English is becoming increasingly important. As is known to all, pronunciation is a significant part of a language, which is complex and flexible. Chinese learners with a fluent and native English will benefit a lot. But the fact is that Chinese learners who have learned English as a second language for a long time still have lots of different problems on English pronunciation because of the interference of mother tongue. Therefore, based on language transfer theory, this paper intends to show different English pronunciation problems of learners in several areas-Northwest China, Central China, Northeast China and Southern China. By comparing Chinese and English phoneme families, the reasons of the problems in these areas will be analyzed. This paper aims to alleviate English pronunciation problems in these areas. What's more, it is expected that this paper will be useful in teaching of English pronunciation.
\end{abstract}

Index Terms - negative transfer, mother tongue, English pronunciation

\section{INTRODUCTION}

In a society under the trend of English learning, English has become an indispensable part of everyone's life. There are some reasons for it. First, English is one of the major international languages in the world today. It has been the most widely used language and it will continue to be so. According to the study in 1986, the world's native English speakers are nearly 400 million, which means almost one in ten people speaks English as their native language (Liu, 2011). In addition, there are about 20 countries in the world using English as their official language or the second language, with an estimation of 800 million people. Second, English is widely used all around the world. A great number of the world's e-mail is written in English. What's more, a large proportion of radio programs worldwide are conducted in English. Meanwhile, it is one of the official languages of the United Nations. Furthermore, under the situation of globalization, English is a crucial tool for cooperation between countries in many fields.

But through observation and existing information, it is found that lots of English learners have problems in learning English, including pronunciation, grammar, semantics and so on, no matter which country they are from or what nationality they are. English pronunciation is the foundation of other aspects. This paper focuses on English pronunciation problems in different areas in China. It's unavoidable that in China, a variety of English learners in different areas can't pronounce every English phoneme or word correctly. For example, some learners pronounce vehicle ['vi:əkl] as ['wr:əkl]. They pronounce only ['əonli] as ['əolı], map [mæp] as [mæpu], etc. Meanwhile, some learners can't distinguish [n] and [1]. They often mispronounce [1] as [n]. Here is a joke about English pronunciation problem. Once, a Chinese student studying abroad had a discussion with his landlord on the secrets of staying up late. The student said he would eat some snacks to keep a clear mind. But what the landlord heard was that he would eat some snakes. It made landlord feel so scared when imagining such a picture that the student kept snakes and ate them.

So why do these pronunciation problems exist? First, it's because English and Chinese belong to different language families. Chinese belongs to Sino-Tibetan language family, while English belongs to Indo-European language family (Lei, 2012). When it comes to different areas, it is the dialect of different areas that is quite different from English phonemes. Second, Some English phonemes don't exist in the dialects of some areas of China. It's easy for learners in these areas make pronunciation mistakes. Third, most learners do not have enough exposure to an English-speaking environment to acquire native-like pronunciation. So when learners learn English, language transfer occurs inevitably and all these factors influence pronunciation together. In former studies, a large number of researches focus mainly on the pronunciation problem in a certain area of China, ignoring the differences among several areas in one paper. Therefore, based on language transfer theory, through reviewing existing literature and information, this paper will analyze English pronunciation problems in Northwest China, Central China, Northeast China and Southern China - confusion with phonetic pairs, failure to distinguishing long vowels and short vowels, adding a phoneme. This paper finds reasons of each problem and gives solutions accordingly. It is expected that this paper can provide some useful reference for English learners in China and for English teachers as well.

\section{Methodology}


Language acquisition is one of the quintessential human traits (Friederici, 2011), because non-humans do not communicate by using language (Kosslyn, 1995). Now, most learners have to learn a second language after they have acquired their mother tongue. The process of their learning a second language is the process of second language acquisition. Second language acquisition, formally established itself as a discipline around the 1970s, refers to the systematic study of how one person acquires a second language subsequent to his native language (Dai, 2016). During this period, mother tongue will surely have an influence on second language. This is language transfer. Transfer originally is a psychological term that refers to the effect of previous learning or skills on subsequent learning or skills (Wu, 2011). Rod Ellis refers to language transfer as "any instance of learner data where a statistically significant correction is shown to exist between some feature of the target language and any other language that has been previously acquired" (Ellis, 2013). Kellerman holds the view that language transfer is "those processes that lead to the incorporation of elements of one language into another" (Kellerman, 1986). Odlin gives a more acceptable definition of language transfer based on previous definitions: Language transfer is the influence resulting from the similarities and differences between the target language and any other language that has been previously acquired (Odlin, 1989). Thus, from above, in second language acquisition, the influence of mother tongue on learners is commonplace. In the process of second language acquisition, learners' mother tongue will directly influence learners' second language acquisition. It can be divided into two parts: positive transfer and negative transfer. When two languages are similar, it will cause positive transfer. On the contrary, when two languages are widely different from each other, it will cause negative transfer (Weinreich, 1953). It is also called interference. Positive transfer can promote learners' mastery and usage of a second language, while negative transfer will interfere with learners' second language acquisition.

In second language acquisition, learners usually transfer the pronunciation habits and rules of their mother tongue to second language, which is the process of brain processing new knowledge. The degree depends on how great the similarities or differences are between mother tongue and the second language. Nowadays, English is so important that a great number of countries select it as a second language, including China. However, between English and Chinese, the similarities are much less than the differences, which can be seen in various perspectives — pronunciation, vocabulary, grammar, pragmatics and so on. As for pronunciation, English and Chinese belong to different language families. Meanwhile, Chinese is timed with syllables, while English is timed with stress. As a consequence, negative transfer of Chinese is larger than positive transfer when Chinese learners learn English pronunciation. It means when studying English, Chinese learners will be inevitably interfered by Chinese pronunciation habits to a certain extent. Most English learners in contemporary China have problems of English pronunciation, which is mainly caused by the interference of mother tongue. Consequently, it is not easy for English learners to learn English pronunciation natively. China is such a large country that it has a vast territory and huge population. Consequently, there are many different dialects in various areas. They have their own pronouncing rules. When learners in different areas learn a new language - English, they will apply the phonemes and pronouncing rules to English. But there are a range of differences between Chinese and English pronunciation. Naturally, many English pronunciation problems spring out. This paper intends to analyze different pronunciation problems in four areas of China-Northwest China, Central China, Northeast China and Southern China and offer some solutions.

\section{Results of INFluence of Negative Transfer of CHINESE}

\section{A. In Northwest China}

Pronunciation problems are that learners mispronounce some consonants or diphthongs as other combinations of phonemes. Learners in this area can't make a clear distinction between [n] and [1], [ei] and [en], [u] and [əo]. The confusion between $[\mathrm{u}]$ and $[\partial v]$ mainly occurs in Shaanxi Province. All these are caused by their problems of distinguishing several Chinese phoneme pairs in their dialects. Here are some examples.

Sample 1: [n] and [1]

\begin{tabular}{|c|c|c|}
\hline WORDS & STANDARD PRONUNCIATION & LEARNERS' PRONUNCIATION \\
\hline name & [neIm] & [leIm] \\
\hline negative & ['negətIv] & ['legatıv] \\
\hline niece & [ni:s] & [li:s] \\
\hline nature & ['neitfo] & ['leitfə] \\
\hline \multicolumn{3}{|c|}{ Sample 2: [ei] and [en] } \\
\hline WORDS & STANDARD PRONUNCIATION & LEARNERS' PRONUNCIATION \\
\hline pen & [pen] & [peI] \\
\hline hey & [heI] & [hen] \\
\hline mend & [mend] & [meId] \\
\hline wait & [weIt] & [went] \\
\hline
\end{tabular}


Sample 3: $[\mathrm{u}]$ and $[\partial 0]$

\begin{tabular}{|c|c|c|}
\hline WORDS & STANDARD PRONUNCIATION & LEARNERS'PRONUNCIATION \\
\hline book & [bok] & [bəok] \\
\hline good & [god] & [gəod] \\
\hline full & [foll] & [fəol] \\
\hline hook & [hok] & [həok] \\
\hline
\end{tabular}

Therefore, in Northwest China, learners' problems are confusions with the phonetic pairs including both vowels and consonants. The dialects in northwest China surely have a significant effect on learners' English pronunciation and this problem is hard to be settled.

\section{B. In Central China}

Learners have confusion of phonetic pairs and there are no long or short vowels in dialect in Central China. As a result, learners in this area are confused with these phonetic pairs: [n] and [l], [u:] and [v], [i:] and [i], [w] [f] and [v], [f] and $[\mathrm{h}]$. There was once an experiment conducted by Qin. The long vowel [i:] only lasted for $0.165764 \mathrm{~s}$ when some learners pronounced "sheep". But actually, the standard length should last for 0.241405s (Qin, 2009). The length of [i:] was cut into half. In general, the length of long vowels needs to be twice as long as short vowels. Learners' confusion with [w], [f] and [v] mainly occurs in Yiyang, Zhuzhou, Yueyang - cities in Hunan Province, as well as their surrounding areas and Henan Province. And the problem between [f] and [h] mainly happens in Hubei Province and Hunan Province. Here are some examples.

Sample 1: [n] and [1]

\begin{tabular}{|l|l|l|}
\hline WORDS & STANDARD PRONUNCIATION & LEARNERS' PRONUNCIATION \\
\hline night & {$[$ nart] } & {$[$ latt] } \\
\hline nice & {$[$ nats $]$} & {$[$ lass $]$} \\
\hline note & {$[$ nəot $]$} & {$[$ ləovt] } \\
\hline natural & {$[$ 'nertfral] } & {$[$ 'lertfral] } \\
\hline
\end{tabular}

Sample 2: [w], [f] and [v]

\begin{tabular}{|l|l|l|}
\hline WORDS & STANDARD PRONUNCIATION & LEARNERS' PRONUNCIATION \\
\hline want & {$[\mathrm{wnnt}]$} & {$[$ vvnt $]$} \\
\hline find & {$[$ faind $]$} & {$[$ vaind $]$} \\
\hline when & {$[$ wen $]$} & {$[$ ven] } \\
\hline west & {$[$ west $]$} & {$[$ [vest $]$} \\
\hline
\end{tabular}

Sample 3: [u:] and [v], [i:] and [i]

\begin{tabular}{|c|c|c|}
\hline WORDS & STANDARD PRONUNCIATION & LEARNERS' PRONUNCIATION \\
\hline fool & [fu:l] & {$[\mathrm{fol} l]$} \\
\hline sleep & [sli:p] & [slip] \\
\hline feet & [fi:t] & [fit] \\
\hline hoop & [hu:p] & [hop] \\
\hline
\end{tabular}

Sample 4: [h] and [f]

\begin{tabular}{|l|l|l|}
\hline WORDS & STANDARD PRONUNCIATION & LEARNERS' PRONUNCIATION \\
\hline who & {$[\mathrm{hu}:]$} & {$[\mathrm{fu}:]$} \\
\hline foot & {$[\mathrm{fut}]$} & {$[\mathrm{hot}]$} \\
\hline fill & {$[\mathrm{fil}]$} & {$[\mathrm{hll}]$} \\
\hline full & {$[\mathrm{ful}]$} & {$[\mathrm{hol}]$} \\
\hline
\end{tabular}

These samples indicate that there are many pronunciation problems existing in this area and the reasons are variable, which increases the difficulty in alleviating the influence of negative transfer of mother tongue.

\section{In Northeast China}

In this area, pronunciation problems are that learners are confused with some phonetic pairs. Also, they replace short vowels with other vowels. Learners in Northeast China mispronounce [ $\left.\int\right]$ as [s], [e] as [æ]. Meanwhile, they substitute [1] for [r]. Besides, learners in Northeast China mispronounce semi-vowel [j] as yi and they can't make a clear distinction between long vowels and short vowels. Some phonemes don't exist in their dialects or Chinese, which accounts partly for the phenomena. Here are some examples.

Sample 1: [J] and [s]

\begin{tabular}{|c|c|c|}
\hline WORDS & STANDARD PRONUNCIATION & LEARNERS' PRONUNCIATION \\
\hline sheep & [ji:p] & [si:p] \\
\hline share & [ $\mathrm{fer}]$ & [sea] \\
\hline shape & [ [erp] & [seip] \\
\hline shine & [Jain] & [sam] \\
\hline
\end{tabular}


Sample 2: [e] and [æ]

\begin{tabular}{|c|c|c|}
\hline \\
\hline WORDS & STANDARD PRONUNCIATION & LEARNERS' PRONUNCIATION \\
\hline head & [hed] & [hæd] \\
\hline wet & [wet] & [wæt] \\
\hline let & [let] & [læt] \\
\hline hesitate & ['hezitert] & ['hæzitert] \\
\hline \multicolumn{3}{|c|}{ Sample 3: $[\mathrm{r}]$ and $[1]$} \\
\hline WORDS & STANDARD PRONUNCIATION & LEARNERS' PRONUNCIATION \\
\hline robot & ['rəobbt] & ['ləubvt] \\
\hline run & {$[\mathrm{r} \Lambda \mathrm{n}]$} & {$[\mathrm{l} \mathrm{nn}]$} \\
\hline crude & [kru:d] & [klu:d] \\
\hline write & [rart] & [lart] \\
\hline \multicolumn{3}{|c|}{ Sample 4: [r] and [i:] } \\
\hline WORDS & STANDARD PRONUNCIATION & LEARNERS' PRONUNCIATION \\
\hline it & [It] & [i:t] \\
\hline is & [Is] & [i:s] \\
\hline wit & [wit] & [wi:t] \\
\hline hit & [hit] & [hi:t] \\
\hline
\end{tabular}

As is seen, in this area, learners also have lots of pronunciation problems. Some problems are unique, which makes it more arduous to weaken the influence of negative transfer of their dialects.

\section{In Southern China}

There are not many consonants or consonant clusters in the dialects in Southern China. Meanwhile, places of articulation of some consonants are different from those of English.. Therefore, in this area, pronunciation problems are that learners can't make a clear distinction between [r] and [1]. They mispronounce [r] as [1](Shi, 2013). Learners in Guangdong Province also mispronounce [v] as [w]. Here are some examples.

\begin{tabular}{|c|c|c|}
\hline WORDS & STANDARD PRONUNCIATION & LEARNERS' PRONUNCIATION \\
\hline map & [mæp] & [mæpv] \\
\hline blue & [blu:] & [bəlu:] \\
\hline please & [pli:z] & [po'li:z] \\
\hline blow & [bləu] & [biləo] \\
\hline \multicolumn{3}{|c|}{ Sample 2: [v] and [w] } \\
\hline WORDS & STANDARD PRONUNCIATION & LEARNERS' PRONUNCIATION \\
\hline vest & [vest] & [west] \\
\hline victory & ['vIkt(ə)rI] & ['wIkt(ə)rI] \\
\hline vice & [vaIs] & [wais] \\
\hline value & ['vælju:] & ['wælju:] \\
\hline \multicolumn{3}{|c|}{ Sample 3: [r] and [1] } \\
\hline Words & Standard pronunciation & Learners' pronunciation \\
\hline right & [rait] & [lait] \\
\hline robot & ['roubpt] & ['ləubpt] \\
\hline reference & ['ref(ə)r(ə)ns] & 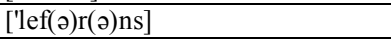 \\
\hline rote & [rovt] & [ləut] \\
\hline
\end{tabular}

In this area, some problems are similar to those in others areas. They have been mentioned above. But it still has its unique pronunciation problems. At the meantime, there are some other problems which still need further discovering, for what are listed are mispronounced ones.

Obviously, from these problems, we can see Chinese learners come across a lot of problems during the process of pronouncing English phonemes and words, including phonetic pairs, distinction between long vowels and short vowels, phonemes, etc. They have been shown through above examples. But we all know that mispronunciation of a certain word can lead to different meanings and sometimes even bring trouble and misunderstanding. As is shown in the above statements, there are a few similar English pronunciation problems among different areas, while the differences take up the majority.

\section{AnAlysis of the Reasons of DifFERENT ENGLish PRONUNCIATION PROBLEMS IN DifFERENT AREAS}

\section{A. Interference of Chinese Phoneme Pairs}

In northwest China, the reasons are that learners mispronounce Chinese mandarin lei as nei, nai as lai. And the pronunciation of Chinese phonemes $l$ and $n$ are the same as that of English [1] and [n]. It means if a student can pronounce Chinese phonemes $l$ and $n$ correctly, his English [1] and [n] won't be wrong. What's more, in the dialect of Northeast China, learners mispronounce Chinese mandarin $d u$ as $d o u, t u$ as $t o u$. And in Chinese mandarin, when en was 
after $b, p, m, f$, learners in Shaanxi Province are easy to mispronounce en as ei. For instance, learners in this area mispronounce ben as bei, pen as pei, men as mei, fen as fei. So it's evident that learners in Northwest China can't distinguish these Chinese phonemes clearly in their dialects or to say, it's their dialects that result in these pronunciation problems between [n] and [1], [ei] and [en], [u] and [əv] in English.

\section{B. Confusion of Phonetic Pairs and No Long or Short Vowels in the Dialects}

In Central China, especially in Hunan Province and Henan Province, learners mispronounce Chinese mandarin fan and wan as van, fei and wei as vei. They mispronounce Chinese phonemes $v$ and $w$ in their dialects. This is also caused by their error between $h$ and $f$. For example, they mispronounce $h u a$ as $f a, f e i$ as hui, etc. The confusion between [n] and [1] originates from their dialects, too. In some areas of Hunan Province and Hubei Province, learners are often required to speak such a sentence-Grandmother Liu likes drinking milk. Many people may be puzzled about it. That's because in Chinese, it is pronounced as Liu Nainai ai he niu nai, while learners in these areas will mispronounce it as Liu Lailai ai he liu lai. They mispronounce na as la, neng as leng, etc. And they usually mispronounce $l$ as $n$, since they can't correctly pronounce $n$ and $l$ in their dialects. As mentioned in Northwest China, the pronunciation of Chinese phonemes $l$ and $n$ are the same as that of English [1] and [n]. So we can see it is their mispronunciation in their dialects that results in these problems. With regard to learners in this area who can't make a clear distinction between long vowels and short vowels, the reason is that in English, there are 20 vowels and 24 consonants. The 20 vowels can be divided into 12 monophthongs and 8 diphthongs. The 12 monophthongs can be further divided into 5 long vowels and 7 short vowels. In Chinese mandarin, there are 39 vowels that are divided into 10 single vowels and 29 compound vowels. But Chinese mandarin doesn't classify vowels according to their length. So there are also no long and short vowels in the dialects of Hunan Province. Therefore English long vowels cannot be pronounced long enough by learners in Hunan Province, as well as other places in Central China.

\section{Confusion of Phonetic Pairs and Lack of Certain Phonemes in the Dialects}

Chinese mandarin, $z, c, s$ are blade-alveolar, and $z h, c h$, sh are cacuminals. In Chinese mandarin, cacuminals are commonly used. But in the dialects of Northeast China, blade-alveolar occupies the majority. Learners in Northeast China mispronounce most of the cacuminals as blade-alveolar. For an instance, they mispronounce $s h i$ as $s i, c h u$ as $c u$, $z h u$ as zu, zhong as zong. Confusion between [ $\left.\int\right]$ and [s] is also caused by confusion in their dialects. In the dialects of Northeast China, there is actually no similar phonemes to the two vowels_— [e] and [æ]. When pronouncing [e], learners' tongue is close to the hard palate and the tip of their tongue is under the tip of the teeth, with their gums half open. It looks as if they are smiling when they do it. While pronouncing [æ], learners' lips are flat and their tongues slightly rise. Meanwhile, the tip of their tongue is against their gingiva, with their gums open and soft palate rising. What' more, their lips are naturally open. As is observed and seen above, it is more difficult for learners to pronounce [e] than [æ]. As a consequence, when learners in this area pronounce words with [e], the place of their tongue is lower and more behind than standard ones. Meanwhile, the shape of their mouths is rounder. That is why they mispronounce [e] as [æ]. Furthermore, as is known to all, most northeast people own a very forthright character, which determines the pronunciation of their dialects (Yan, 2011). Their oral muscles are relaxed and robust so that they are not used to the pronunciation with both upper and lower lips tense and angulus oris protracted. But when pronouncing [i:], [i] and [e], learners need to stretch their angulus oris both left and right. Sometimes they even mispronounce [i:] as [I]. If a person's oral muscles are relaxed, they can't pronounce these phonemes correctly.

\section{Lack of Certain Consonants or Consonant Clusters in the Dialects}

In Southern China, learners are accustomed to adding a vowel after a consonant. The reason is that there are consonant clusters in English phonetic system, but in Chinese, the situation is opposite. There are no consonant clusters in the dialects or Chinese and the pronunciation feature is an initial consonant with a simple or compound vowel. Cantonese is a typical example. Whereupon, learners in Guangdong Province who are affected by this phenomena habitually add a vowel after a consonant. As for the confusion between [v] and [w], the reason is that in Guangdong Province, there is no Chinese phoneme $v$ which is similar to English labiodental [v]. As a consequence, learners in Guangdong Province mispronounce [w] as [v]. For instance, they mispronounce wen as ven. So does the confusion between [r] and [1]. There is no such a phoneme that is similar to fricative [r] in the dialects of Southern China. They pronounce both reng and leng as leng. As a result, learners mispronounce [r] as [1].

\section{Discussions of the Solutions to DifFEREnt PronunCiation Problems}

As some of the above pronunciation problems are based on specific and unique conditions, it's impossible to get rid of them once and for all. But, something can still be done. First, learners must be aware that they have English pronunciation problems. Second, they must be persistent and spare no efforts to improve their pronunciation.

As for the mispronunciation problem which results from mispronunciation in their dialects, the best way is to use the method of phonetic contrast. As is mentioned above, learners can't make a clear distinction between English phonetic pairs. They need to alleviate their English pronunciation problems. First, starting from the beginning, these learners should relearn their frequently mispronounced phoneme pairs, both Chinese and English. During the process, they 
should not only compare the difference of different phonemes, but also the difference between Chinese and English phonemes. It is the preliminary step and the most crucial step which lays the foundation for later steps. Second, learners can search for a listening material and then listen to standard pronunciation to compare the differences between their pronunciation and standard pronunciation. In most cases, learners can't understand the differences between their pronunciation and standard pronunciation so that they mispronounce these phonemes. The listening material could be BBC learning English for China. Of course, it would be better for them to choose more interesting podcast, such as 6 Minute English, Forum a World of ideas, Luke's English Podcast, etc. After all, learners also concentrate on the contents of the materials when they are listening. The best listening material should be those that suit themselves. After this, learners should carry on repeated imitation practice by following the video and make a conscious effort to correct their pronunciation problems. It requires daily practice for one to two hours at a time. No matter how much one knows about standard English pronunciation, only when he speaks it out can he make a difference. What's more, learners can also observe the pronunciation of high-level English learners. It's also a useful way to make a comparison to find the differences and imitate more acceptable pronunciation of others. In the end, it calls for constant practice by listening and following the listening material. By doing so, pronunciation problems caused by mispronunciation from dialects can gradually be lessened.

For the mispronunciation problem which results from lack of certain phonemes in their dialects or different places of articulation of two different languages, the best solution is to use the method of picture of place of articulation with teacher's help. Teachers should explain the ways how these phonemes are pronounced with the picture of place of articulation. And they should explain front vowels, mid vowels and back vowels according to the position of tongue (Wu, 2011). Furthermore, bilabial, labiodental, dental, alveolar, palatal, velar, glottal and consonant clusters can be explained according to the places of articulation. For instance, when pronouncing [v], the upper teeth touch the lower lip and speaker forces the breath out from the gap between the lips and teeth. It requires vocal cords vibrated. When pronouncing $[\mathrm{w}]$, the lips are protruding and pointed-rounded, with tongue rising to the soft palate and breath flowing through the vocal cords. Vocal cords also need to be vibrated. After explanation, teachers need to demonstrate the correct pronunciation and ask their students to observe the shape of their mouths. In addition, learners need to pronounce phonemes loudly and clearly after demonstration. This can make learners feel the change of their vocal organs. Therefore, they can eliminate their pronunciation problem from root.

For the mispronunciation problem which results from learners' forthright character in Northeast China, learners can use the method of cavity and face muscles training. Almost all the countries throughout the world, including China, choose British English as a second language. Most of the places of articulation of British English phonemes are widely different from the dialects of Northeast China. Therefore, these learners need to weaken the problem of flaccid cavity and face muscles. They are supposed to have some targeted cavity and face muscle training, such as piping the yeasty barrel, playing the flute or whistling. At the same time, learners can keep warm salt water or soda in their mouths and contract their cavity muscles to force the water from the gap between the teeth to the outside of teeth. After that, their cheek muscles compress the water to the back of the mouth. Having such kind of training similar to mouthwash for 5 to 6 times in the morning and evening can stimulate the muscles around the mouth and facilitate blood circulation. Meanwhile, it can increase cavity muscle tone and improve the situation of flaccid cavity muscle. Last but not least, learners in this area are supposed to breathe through mouth less and sleep with mouth closed. Because breathing through mouth makes people's cavity and face muscles more flaccid.

\section{CONCLUSION}

All in all, when learning English pronunciation, it is inevitable for Chinese to understand that mother tongue will interfere with their English pronunciation. Negative transfer of mother tongue is responsible for it. After analyzing some cases, it can be concluded that Chinese learners have many problems in English pronunciation. Some reasons are presented. In this paper, many examples are shown to illustrate the different English pronunciation problems in different areas. Some solutions are put forward accordingly as well, including the method of phonetic contrast, place of articulation and cavity and face muscles training. In order to correct these problems, learners need to make a clear distinction between Chinese and English phonetic systems. At the same time, learners themselves and teachers ought to attach great importance to English pronunciation. It is strongly believed that through long-term adherence and scientific training, learners' English pronunciation will be improved.

But this paper also has some deficiencies certainly. As is known, these English pronunciation problems of Chinese learners are rooted out. Learners can only make great efforts to decrease the influence of negative transfer of mother tongue. Since this paper is just an exploratory research of negative transfer of mother tongue, more studies need to be furthered and carried out. More experiments need to be conducted to check out the feasibility of these solutions. Meanwhile, this paper only illustrates four areas of China and some representative and typical problems in these areas. Other areas and other problems are not included. It is expected that this paper can make some contribution to the study of negative transfer of mother tongue and weakening its influence on second language acquisition. Another expectation is that it could provide some implications for English pronunciation teaching. Furthermore, English pronunciation is the basis of semantics, grammar, translation, discourse, etc. The less English pronunciation problems Chinese learners have, the more likely they are to master English and put it into use. 


\section{REFERENCES}

[1] Dai Weidong \& He Zhaoxiong. (2016). A New Concise Course in Linguistics for Students of English. Shanghai: Shanghai Foreign Language Education Press.

[2] Ellis R. (2013). The Study of Second Language Acquisition. Shanghai: Shanghai Foreign Language Education Press.

[3] Friederici, AD. (2011). The Brain Basis of Language Processing: From Structure to Function. Physiological Review(4): 1357-92.

[4] Jia Xiuzhi. (2016). An Analysis of Language Transfer's Influence on English Pronunciation Learning. Overseas English(4): 237-240.

[5] Kellerman E. \& Sharwood S. (1986). Cross Linguistic Influence in Second Language Acquisition. Oxford: Pergamon Press.

[6] Kosslyn, Stephen M. \& Osherson, Daniel N. (1995). An Invitation to Cognitive Science. Cambridge, Massachusetts: MIT Press

[7] Lei Xuhui (2012). The Intervention of Negative Transfer of Native Culture to EFL Learning. Journal of Southwest Agricultural University (12): 111-113.

[8] Liu Aijun (2011). Language and Psychological Preparation for the Foreign Affairs Report of Great International Conferences. Journalist Cradle (5): 32-33.

[9] Odlin T. (1989). Language Transfer: Cross-Linguistic Influence in Language Learning. Cambridge: Cambridge University Press.

[10] Qin Xi, Wang Hongmei, Yang Jie, Wang Liying, He Tianjing. (2009). The Influence of Hunan Dialect on English Pronunciation. Digest of Management Science (4): 161-162.

[11] Ren Suzhen. (2011). Analysis of the Influence of Shaanxi Dialect Pronunciation on English Pronunciation. Shaanxi Education (4):34-35.

[12] Shi Jinrong. (2013). A Study of Cantonese's Negative Transfer on English Pronunciation and Teaching Strategies. Central China Normal University.

[13] Weinreich U. (1953). Language in Contact: Findings and Problems. The Hague: Mouton.

[14] Wu Rong (2011). The Research on the Phenomenon of Negative Transfer in Learning English Phonetics--On the Negative Transfer of Pronunciation and Intonation of Nanxian Dialect on Secondary Specialized learners. Central China Normal University.

[15] Yan Yongqi, Yang Xiujuan. (2011). The Influence of Northeast Dialect on College learners' English Phonetics and Preliminary Research on Teaching Strategies. China Daily Innovation Herald(1): 163.

Tingting Zheng was born in Quzhou, China in 1997. She is currently a junior of Foreign Language College, Zhejiang Ocean University, majoring in English Teaching.

Qi'ang Liu was born in Zhoushan, China in 1978. She is a Master of Arts in Literature and Language of Zhejiang Normal University, China in 2009.

She is currently an Associate Professor of Foreign Language College, Zhejiang Ocean University, China. Her research areas are in English Teaching and Scientific Research. 